\title{
In rats with estradiol valerate-induced polycystic ovary syndrome, the acute blockade of ovarian $\beta$-adrenoreceptors improve ovulation
}

Berenice Venegas ${ }^{1,2}$, Lizzbeth Yureli De León Gordillo', Gabriela Rosas ${ }^{1}$, Julieta A. Espinoza ${ }^{1}$, Carolina Morán³, Roberto Domínguez ${ }^{1}$ and Leticia Morales-Ledesma ${ }^{1 *}$ (i)

\begin{abstract}
Background: Polycystic ovary syndrome is characterized by hyperactivity of the ovarian sympathetic nervous system, increases in the content and release of norepinephrine, as well as decreases in the number of $\beta$-adrenoreceptors. In the present study, $\beta$-adrenoreceptors in the ovaries of rats with polycystic ovary syndrome were blocked and analyzed the resultant effects on ovulation, hormone secretion and the enzymes responsible for the synthesis of catecholamines. Methods: At 60 days of age, vehicle or estradiol valerate-treated rats were injected with propranolol $\left[10^{-4} \mathrm{M}\right]$ into the ovarian bursas on oestrus day. The animals were sacrificed on the next day of oestrus, and the ovulation response, the steroid hormone levels in the serum and the immunoreactivity of tyrosine hydroxylase and dopamine $\beta$-hydroxylase in the ovaries were measured.

Results: In animals with the induction of polycystic ovary syndrome and $\beta$-adrenoreceptor blocking, ovulation was restored in more than half of the animals and resulted in decreased hyperandrogenism with respect to the levels observed in the estradiol valerate-treated group. Tyrosine hydroxylase and dopamine $\beta$-hydroxylase were present in the theca cells of the growing follicles and the interstitial gland. Injection of propranolol restored the tyrosine hydroxylase and ovarian dopamine $\beta$-hydroxylase levels in rats with polycystic ovary syndrome induction.

Conclusions: The results suggest that a single injection into the ovarian bursas of propranolol, a nonselective antagonist of $\beta$-adrenoreceptor receptors, decreases the serum testosterone concentration and the formation of ovarian cysts, improving the ovulation rate that accompanies lower levels of tyrosine hydroxylase and dopamine $\beta$ hydroxylase in the ovary.
\end{abstract}

Keywords: PCOS, $\beta$-Adrenergic receptors, Steroid hormones, Ovarian innervation, Ovulation

\section{Background}

Polycystic ovarian syndrome (PCOS) is the most common cause of infertility in women of reproductive age. It has a prevalence between 6 and 10\% based on the U.S. National Institutes of Health criteria and 15\% when the Rotterdam criteria are applied [1, 2]. PCOS is a multifactorial pathology that is characterized by hyperandrogenism,

\footnotetext{
* Correspondence: moralesledesma@yahoo.com.mx

${ }^{1}$ Biology of Reproduction Research Unit, Physiology of Reproduction

Laboratory, Facultad de Estudios Superiores Zaragoza, UNAM, AP 9-020, CP,

15000 México, DF, Mexico

Full list of author information is available at the end of the article
}

anovulation, presence of multiple ovarian cysts, irregularities in the menstrual cycle, and variable levels of gonadotropins $[3,4]$. The etiology of PCOS is unknown, but intrinsic abnormalities in the synthesis and secretion of androgens are a probable basis for the syndrome [5]. Additionally, involvement of the sympathetic nervous system that innervates the ovaries during the development of the syndrome is suggested by studies in women with PCOS, where a high density of catecholaminergic nerve fibers has been shown [6]; further, in rats, the participation of sympathetic nerve fibers in the modulation of androgen secretion in the ovaries has been revealed [7], which may

(c) The Author(s). 2019 Open Access This article is distributed under the terms of the Creative Commons Attribution 4.0 International License (http://creativecommons.org/licenses/by/4.0/), which permits unrestricted use, distribution, and 
contribute to the etiology of PCOS [8]. In rats, the main catecholamine present in the ovaries is norepinephrine (NE), which stimulates steroidogenesis [9-11], follicular development [12-15] and ovulation [16-18] by regulating $\alpha$ - and $\beta$-adrenoreceptors (ADR) [19-21].

There is evidence that nonhormonal procedures result in PCOS. Luna et al., [22] showed that peripheral stimulation of $\beta$-adrenoreceptors (ADRB) with isoproterenol in wild-type adult rats promotes an increase in the number of precystic and cystic ovarian follicles without changes in plasma steroid levels, while blocking ADRB with propranolol in the same model inhibits their formation. The authors suggested that stimulation of ADRB activates the sympathetic nervous system of the rat ovary, which could be one mechanism of PCOS development and that they could be a therapeutic alternative for women with PCOS [22]. Fernandois et al. [23] showed that the prolonged blockade of $\beta 1$ and $\beta 2$-adrenoreceptors in 8- and 10month rats, by i.p. daily injection of propranolol $(5 \mathrm{mg} / \mathrm{kg}$ of body weight), during 60 days, recovered estrous cyclicity, elevated the ovulation rate, and levels of serum sexual steroids. We have previously shown that in the cyclic rat the acute blockade of $\beta 1$ and $\beta 2$-adrenoreceptors by propranolol injection at different days of the estrous cycle reduced the number of ova shed only in those animal treated on diestrus 2 , without affecting ovulation in the other day of the cycle [24].

Several experimental models have been proposed to induce PCOS in neonatal, prepubertal or adult rats, depending on the phenotypic and physiological characteristics that are to be investigated, such as steroidal and nonsteroidal drugs (dehydroepiandrosterone, dihydrotestosterone, letrozole, and estradiol valerate (EV)-administration) [25-27] and genetic or environmental manipulations (genetically modified rat models as well as models developed with exposure to constant light or stress) $[28,29]$. To study the relationship between the PCOS and sympathetic innervations, the most commonly used PCOS model is generated by a single injection of $\mathrm{EV}$ in prepubertal rats, which results in a polycystic ovary morphology, irregular estrous cycles [30, 31], alterations in basal and pulsatile luteinizing hormone (LH) concentrations and follicle stimulating hormone (FSH) concentrations and an increased androgen response to human chorionic gonadotropin stimulation [32]. The ovaries of rats injected with EV presented increased neural sympathetic activity $[8,32-34]$. This increase is due to changes in the homeostasis of ovarian catecholamines that begin before the development of cysts and persist after their formation [8]. This change is accompanied by an increase in the release and content of NE from the nerve terminals to the ovary, an increase of tyrosine hydroxylase $(\mathrm{TH})$ activity, the limiting enzyme for the synthesis of catecholamines, and a down regulation of ADRB2 in theca interstitial cells $[8,32,35]$.
Previous studies have analyzed the participation of ovarian innervation in the development of PCOS in rats following EV injection, and increased activity of the sympathetic nerves of the ovary has been shown. The bilateral sectioning of the superior ovarian nerve (SON) in EVtreated rats restores ovulation [8], while the unilateral section of the SON in the same animal model restores ovulation mainly in the innervated ovary and the NE concentration was decreased only in denervated ovaries [36]. In a previous study [37] we showed that the elimination of noradrenergic fibers by guanethidine injection before the establishment of PCOS prevents the blockade of ovulation and hyperandrogenism. In animals with the PCOS peripheral sympathetic denervation by guanethidine also restores ovulatory capacity, but it was not as efficient in reducing hyperandrogenism. This suggests that the elimination of noradrenergic fibers before the establishment of PCOS prevents two characteristics of the syndrome: blocking of ovulation and hyperandrogenism [37]. Electroacupuncture treatment $[33,38]$ or voluntary exercise [39] in EV-treated rats reduces sympathetic activity, restores the oestrus cycle and ovulation, and normalizes LH secretion and steroidogenesis to regulate ADR.

Based on these evidences the aim of the present study was to analyze if a pharmacological acute blockade of ovarian ADRB restores ovarian functions in the EV model of PCOS.

\section{Materials and methods \\ Animals}

Newborn, female rats of the CII-ZV strain were kept with their mothers under controlled light conditions (lights on from 05:00 to 19:00 h) until weaning and were provided free access to food and water ad libitum under the same light conditions.

The animals were provided by the Facultad de Estudios Superiores-Zaragoza, UNAM, and the Bioethics Committee approved the experimental protocols. All procedures described in the present study were performed in accordance with the Guide for the Care and Use of Laboratory Animals of the Mexican Council for Animal Care (NOM062-ZOO-1999) and to the Guidelines for the Use of Animals in Neuroscience Research from the Society for Neuroscience. Every effort was made to minimize the number of animals in each experimental group and to ensure minimal discomfort and pain.

\section{Experimental designs}

Ten-day-old female rats were intramuscularly injected with $2.0 \mathrm{mg}$ EV (Sigma Chemical Co., St. Louis, Mo. USA) that had been dissolved in $0.1 \mathrm{~mL}$ sesame oil. The vehicle group (Vh) was injected with a single $0.1 \mathrm{~mL}$ dose of sesame oil. Vaginal smear was performed daily after the vaginal opening was first observed. 
At 60 days of age, the animals in vaginal oestrus were randomly assigned to one of the following four experimental groups:

1) Vh group $(n=10)$. Rats treated with sesame oil were sacrificed at 60 days of age, on oestrus day.

2) Vh group plus propranolol $(n=10)$. The ovarian bursas of rats treated with sesame oil were injected with $20 \mu \mathrm{L}$ of propranolol $\left[10^{-4} \mathrm{M}\right.$ ] (Sigma Chemical Co., USA) that was dissolved in $0.9 \%$ saline solution.

3) EV group $(n=8)$. Rats treated with EV were sacrificed at 60 days of age, on oestrus day.

4) EV group plus propranolol $(n=9)$. The ovarian bursas of rats treated with EV were injected with $20 \mu \mathrm{L}$ of propranolol $\left[10^{-4} \mathrm{M}\right.$ ) (Sigma Chemical Co., USA) that was dissolved in $0.9 \%$ saline solution.

\section{Surgery}

Following the methodology previously described [40], each of the rats underwent a bilateral laparotomy under general anesthesia, and the ovaries were exteriorized to enable injection of $20 \mu \mathrm{L}$ of propranolol into each one, with the aid of a Nano-Injector, Stepper Motorized (Stoelting Co, USA) and a $100 \mu \mathrm{L}$ micro syringe (Hamilton, USA) equipped with a 29-gauge needle; the injection rate was $4 \mu \mathrm{L} / \mathrm{min}$. To prevent fluid leakage, the needle was kept in the ovarian bursa for $2 \mathrm{~min}$. Subsequently, the ovaries were carefully cleaned, dried, and returned to the abdominal cavity, and the skin and muscle were sutured. The surgeries were performed between 9:00 and 11:00 A.M.

\section{Autopsy procedures}

Animals from each group were deeply anesthetized with pentobarbital between 9:00 and 11:00 A.M. following confirmation of oestrus by vaginal smear after the surgery. Blood was obtained by intracardiac puncture; it was allowed to clot and was centrifuged for $15 \mathrm{~min}$. at 3000 RPM. The serum was stored at $-20^{\circ} \mathrm{C}$ until progesterone, testosterone and oestradiol levels were measured. The animals were then perfused with a $200 \mathrm{~mL}$ of saline solution followed by $200 \mathrm{~mL}$ of $4 \%$ paraformaldehyde dissolved in a phosphate buffered solution (PBS). At autopsy, the oviducts were dissected, the number of ova shed was counted with the aid of a stereomicroscope, and ovulation was corroborated by observing the presence of corpora lutea (CL).

\section{Ovarian morphology}

The ovaries were dissected and kept in paraformaldehyde for $24 \mathrm{~h}$, rinsed with saline and kept in a PBS solution with $30 \%$ sucrose until histochemical processing. The paraformaldehyde-perfused ovaries were sectioned with a cryostat (Microm HM 525) at temperatures of $20^{\circ} \mathrm{C}$, and the $10-\mu \mathrm{m}$ thick section were subsequently mounted on coated glass slides. Ovarian serially sections of five animals from each group were stained with hematoxylin-eosin and examined under a light microscope. All sections from each group were analyzed for the presence of fresh CL and follicular cysts with a Leica binocular microscope (DM750) coupled to a Leica camera (ICC50 HD). The criteria used to define fresh CL were healthy cells with large nuclei and the presence of blood vessels. The follicular cyst structures were defined according to Brawer et al., [30].

\section{Immunofluorescence to $\mathrm{TH}$ and dopamine $\beta$-hydroxylase (DBH)}

The ovarian sections of three animals taken at random from each experimental group $(\mathrm{Vh}, \mathrm{Vh}+\mathrm{Pro}, \mathrm{EV}$, and $\mathrm{EV}+\mathrm{Pro}$ ), were rinsed with PBS ( $\mathrm{pH}$ 7.4) and were then rinsed twice with PBS with $0.5 \%$ Triton X-100. The nonspecific binding sites were blocked with IgG-free $2 \%$ bovine serum albumin (Sigma Chemical Co., USA). The sections were then incubated overnight at $4-8{ }^{\circ} \mathrm{C}$ with primary antibodies: polyclonal rabbit anti- $\mathrm{TH}$ antibody (1:200 sc-14,007 Santa Cruz Biotechnology Inc., USA) or polyclonal rabbit anti-DBH (1:200 sc- Santa Cruz Biotechnology Inc., USA), and the sections were subsequently incubated with a FITC-labelled goat anti-rabbit secondary antibody (Vector Labs Inc., USA). The slides were counterstained with Vectashield coupled with DAPI (Vector Labs Inc., USA) for nuclear staining. For negative controls, the primary antibody was substituted with PBS. Photomicrographs were taken using an Evolution VF Digital Camera (Media Cybernetics, Inc., USA) coupled with a fluorescence microscope (BX-41 Olympus Co.). From the ovarian sections of each animal, 10 ovarian follicles that exhibited the follicular antrum and the oocyte were selected, except in the cysts where the oocyte is absent ( $n=3$ animals per group with 10 pseudo-replicas per animal). Using the National Institutes of Health's ImageJ software, the relative fluorescent to $\mathrm{TH}$ or $\mathrm{DBH}$ immunoreactivity was quantified following the methodology used previously [37, 40-42] . The color micrographs were converted to 8-bit grayscale images, the criteria used to define the intensity settings were constant between all sections (the selection area in square pixels were equal for each ovarian follicle analyzed). The regions of interest were randomly selected based on the visualization; the fluorescence intensity was quantified in a constant area of each class of follicle evaluated.

\section{Hormone measurements}

The progesterone, testosterone and oestradiol serum levels were measured using a Radio-Immuno-Assay with kits purchased form Diagnostic Products (Los Angeles, CA). 
Progesterone results are expressed in $\mathrm{ng} / \mathrm{mL}$, and testosterone and oestradiol results are expressed in $\mathrm{pg} / \mathrm{mL}$. The intra- and interassay coefficients of variation were 8.35 and 9.45 for progesterone, 9.65 and 10.2 for testosterone, and 8.12 and 9.28 for oestradiol, respectively.

\section{Statistics}

The results were expressed as the mean \pm standard error (SE) for all experiments. The number of ova shed by ovulating rats was analyzed using Kruskal-Wallis tests, followed by a Mann-Whitney U-tests. The ovulation rate, expressed as the number of ovulating animals per number of treated animals, was analyzed using Fisher's exact probability test. Hormone serum levels and immunoreactivity of $\mathrm{TH}$ or $\mathrm{DBH}$ were analyzed using one-way analysis of variance followed by Tukey test, with Graph Pad Software, Inc., (San Diego, CA, USA). A probability $\leq 5 \%$ was considered significant.

\section{Results}

\section{Ovulation rate and number of ova shed (Table 1)}

The animals injected with EV exhibited vaginal opening at $14 \pm 0.0$ days of age and were in oestrus according to the vaginal smear, which remained unchanged until the day of sacrifice. Animals injected with Vh exhibited vaginal opening at $35.1 \pm 1.2$ days of age and had 4-day oestrous cycles.

In the Vh group, all the animals ovulated regardless of whether or not they were injected with propranolol. However, the number of ova shed was smaller in the Vh plus propranolol group than in the Vh group (Table 1).

In the EV group, $1 / 8$ animals ovulated, while in the EV plus propranolol group, $6 / 9$ of the microinjected animals ovulated. The number of ova shed by the EV group microinjected with propranolol was smaller than the number observed in the Vh group (Table 1).

\section{Hormone serum levels}

Microinjection of propranolol in both ovarian bursas of rats treated with Vh did not result in changed progesterone levels compared with the Vh group. Animals injected

Table 1 Ovulatory response in rats with EV and blocking $\beta$ adrenergic receptors in ovaries at 60-day old

\begin{tabular}{llll}
\hline Groups & $N$ & Ovulation rate & Ova shed \\
\hline Vh & 10 & $10 / 10$ & $12.3 \pm 0.7$ \\
Vh + Pro & 10 & $10 / 10$ & $8.4 \pm 1.0^{\mathrm{a}}$ \\
EV & 8 & $1 / 8^{\mathrm{a}, \mathrm{b}}$ & 13 \\
EV + Pro & 9 & $6 / 9^{\mathrm{a}, \mathrm{b}, \mathrm{c}}$ & $4.0 \pm 1.67^{\mathrm{a}}$
\end{tabular}

Ovulation rate and number ova shed in animals treated with vehicle (Vh) or estradiol valerate (EV) at 10 day old and injected with propranolol (Pro) [10 ${ }^{-4}$ $\mathrm{M}][20 \mu \mathrm{L}]$ into the both ovarian bursas at 60 day of age. The animals were sacrificed at next estrus day. Ovulation rate, ${ }^{\mathrm{a}} p<0.05$ vs Vh group, ${ }^{\mathrm{b}} p<0.05$ $\mathrm{Vh}+$ Pro or ${ }^{c} p<0.05$ vs EV group (Fisher's test); number ova shed ${ }^{\mathrm{a}} p<0.05$ vs Vh group (Kruskal-Wallis test) with EV exhibited higher concentrations of progesterone than the controls. The single injection of propranolol within the ovarian bursas in rats with $\mathrm{EV}$ resulted in lower progesterone levels than those observed in EV-injected rats (Fig. 1a).

In the Vh group, propranolol microinjection in both ovarian bursas did not modify testosterone levels compared with Vh-injected group. Testosterone levels in EV animals were higher than those in Vh-injected animals. In these animals, the microinjection of propranolol in both ovarian bursas resulted in lower testosterone levels than EV-treated group but higher testosterone levels than Vh-injected animals (Fig. 1b).

The microinjection of propranolol in Vh-treated animals did not change oestradiol levels compared with Vh-injected rats. The hormone levels in EV-treated animals were higher than those in Vh-treated animals. The microinjection of propranolol into both ovarian bursas resulted in lower oestradiol levels than EV-treatment group (Fig. 1c).

\section{Ovarian morphology}

The ovaries of rats injected with $\mathrm{Vh}$ and microinjected or not with propranolol in both ovarian bursas presented growing follicles at different stages and CL (Fig. 2a and c). The ovaries of rats injected with EV presented follicular cysts, and only the ovaries of a single rat had CL (Fig. 2b). In the ovaries of EV-treated rats that were microinjected with propranolol in both ovarian bursas (Fig. 2d), CL were observed as in the Vh group.

\section{TH and DBH immunoreactivity in ovarian tissue}

The data had a normal distribution (TH fluorescence intensity of follicles with antrum: $p$ value 0.9702 and cyst: p value 0.5176, Shapiro-Wilks normality test). $\mathrm{TH}$ and $\mathrm{DBH}$ immunoreactivity were found only in the interstitial tissue and theca cells of antral follicles. Compared to the Vh group, the $\mathrm{TH}$ immunoreactivity was not significantly different in the ovarian tissue of Vh- propranolol injection-treated rats. The highest intensity of $\mathrm{TH}$ immunoreactivity was observed in the theca cells of the ovarian follicles from the EV group. Propranolol injection into the ovarian bursas in EVtreated rats restored $\mathrm{TH}$ immunoreactivity, with respect to the EV group (Fig. 3).

The microinjection of propranolol did not modify the DBH immunoreactivity in the Vh group. The DBH immunoreactivity in the ovaries of rats injected with EV was higher with respect to the Vh group. Propranolol injection into the ovarian bursas of EV-treated rats restored DBH immunoreactivity in ovarian tissue with respect to the EV group (Fig. 4). 


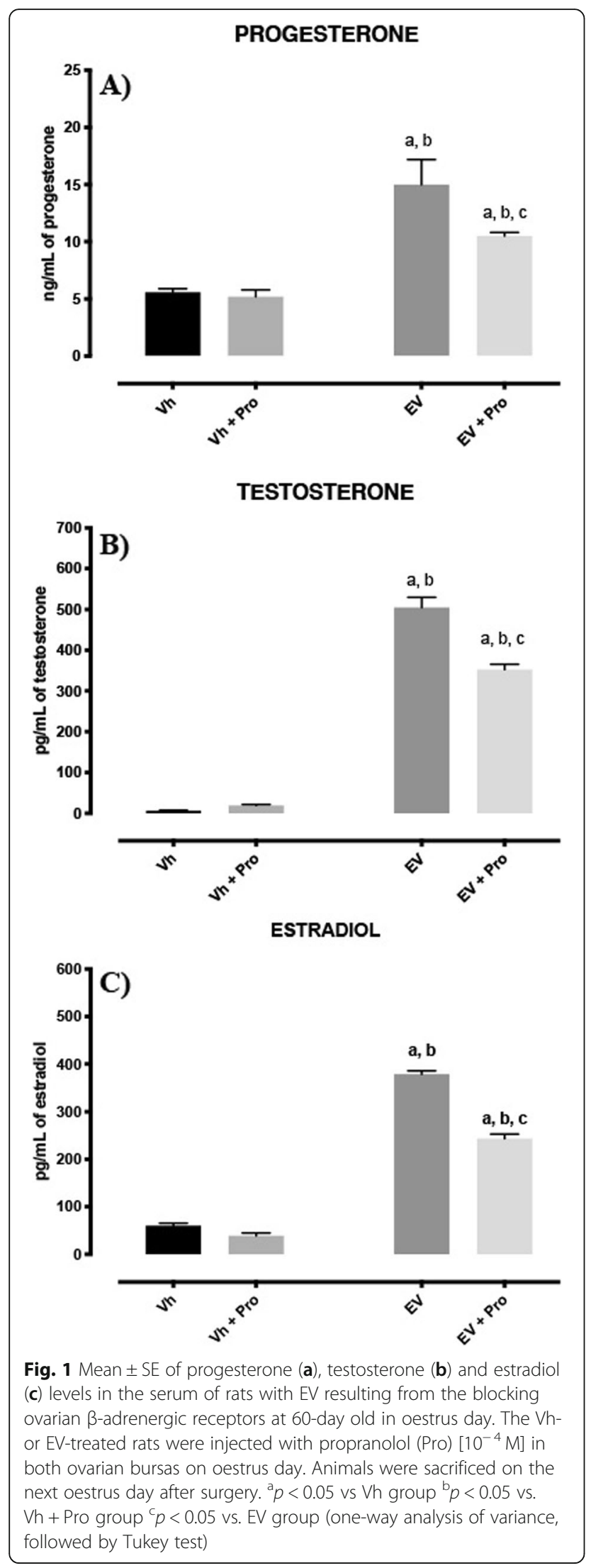

\section{Discussion}

The results of the present study show that acute blocking of ADRB in ovaries with PCOS reestablishes ovulation in more than half of the animals, decreases progesterone, testosterone and oestradiol levels, prevents the development of ovarian cysts (as determined by the observation of ovarian tissue with growing follicles or presence of $\mathrm{CL}$ ), and restores the enzymes responsible for the synthesis of NE to their basal levels.

Hyperactivity of the sympathetic ovarian system has been proposed to be associated with hyperandrogenemia $[5,7,43,44]$; however this relation is not yet clear $[43,45]$. Lara et al. [8] showed that the levels of NE in the ovaries increased slightly at 30 days after an EV injection. When the animals were analyzed 60 days after injection with $\mathrm{EV}$, they had higher levels of ovarian NE and testosterone than the controls did. Rats injected with EV develop PCOS morphology, show a downregulation of ADRB2 and show an increase in the nerve growth factor (NGF) and its low affinity receptors in the ovary $[7,8,32,46]$. This association suggests that NGF [7, 43, 44] induces androgen overproduction in ovaries with PCOS, which is also a result of hyperactivation of the catecholaminergic system on ovarian steroid-secreting cells [32]; however, when the NGF actions were blocked in the ovaries, the ovarian functions are restored [46].

Previous studies have shown that EV-treated rats with unilateral section of the SON restored ovulation by the innervated ovary and normalized the testosterone and oestradiol levels [36]. This result suggests that noradrenergic fibers arrive by SON participate in the hyperandrogenism in the PCOS model. On the other hand, Linares et al. [47] showed that the bilateral section of the vagus nerve (VG) in EV-injected rats restored ovulation in both ovaries, suggesting that the neural information carried by the SON and VG plays a role in the regulatory mechanisms of development and maintenance of PCOS.

Other studies using agonists and antagonists of ADR have suggested that $\alpha$-adrenoreceptors (ADRA) and ADRB are present in the ovaries [10, 11, 19, 48-51]. Consistent with Ojeda and Lara [52] shown that NE acts on ADRB into theca and granulosa cells and stimulates the progesterone and testosterone secretion, but not oestradiol. Likewise, in EV-treated rats, the progesterone and androgen secretion increased in a NE-dependent manner [34].

According to Luna et al. [22], the ovaries of adult rats injected daily with isoproterenol for 10 days, on day 11 secreted a higher amount of androstenedione than the ovaries of the control group. Such increase was not observed in rats studied 30 days after isoproterenol treatment, besides ovarian cysts were still present, the adrenergic activity is similar to the control group, suggesting that after ending the treatment with isoproterenol, the animals 


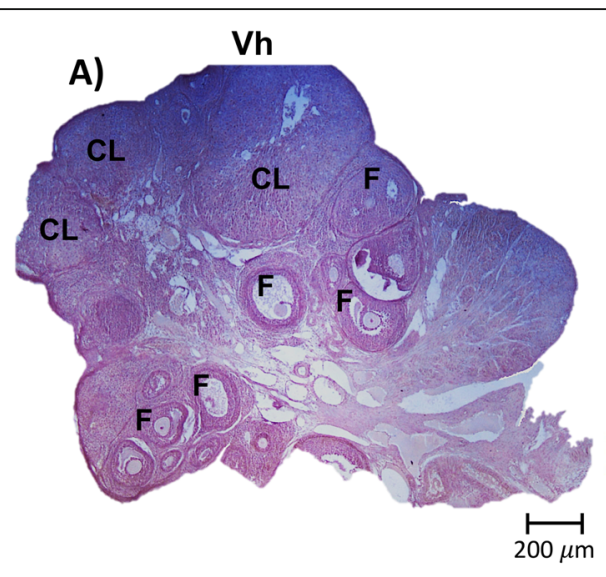

EV

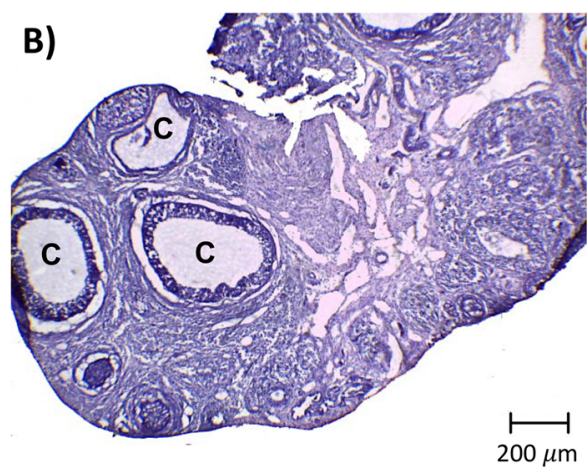

Vh + Pro

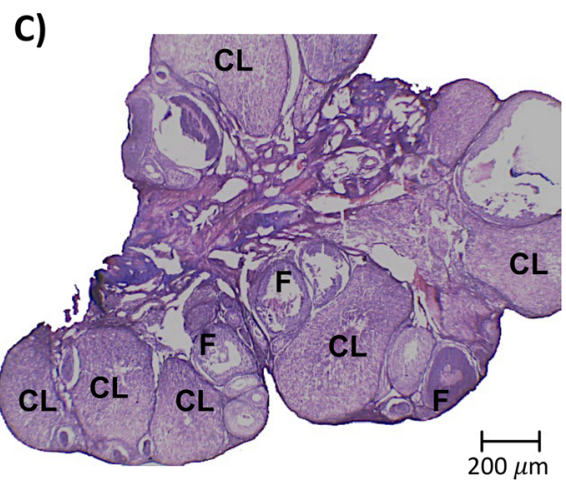

EV + Pro

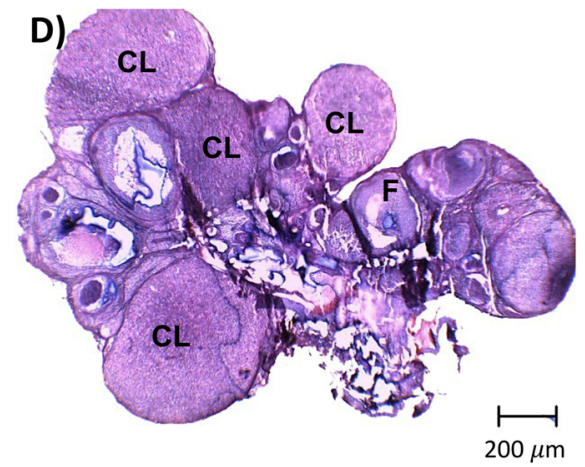

Fig. 2 Ovarian morphology in EV-induced PCOS rats after blocking the ovarian $\beta$-adrenergic receptors at 60 days of age. Representative hematoxylin-eosin-stained $10 \mu \mathrm{m}$-thick sections showing the morphology of the a ovary from Vh-injected rats, $\mathbf{b}$ PCOS ovary from the EV group, c, $\mathbf{d}$ ovary from $\mathrm{Vh}$ - or EV-injected rats and Pro injection $\left[10^{-4} \mathrm{M}\right]$ into the ovarian bursas at 60 days of age, sacrificed at 9:00 A.M. on the next day of oestrus. F: Follicle, C: Cyst, CL: Corpora Lutea. Bar $200 \mu \mathrm{m}$

began their recover. This response is different in EVtreated rats who have hyperandrogenism and hyperactivation noradrenergic for longer periods [8]. After 56 days of EV injection, several groups have described the presence of follicular cysts and ovarian noradrenergic activity remains higher than normal $[8,32,34,36,46,53]$. Then, we suppose that the mechanisms involved in the formation of the polycystic ovary induced by isoproterenol and EV are different.

The findings from this study showed that a single propranolol injection into the ovaries of EV-treated rats improves the ovulation rate, as evidenced by the presence of CL. Moreover, the progesterone and testosterone levels were lower in EV-treated rats and microinjected with propranolol than those treated only with EV; hence, the ADRB blocker begins to restore ovarian steroidogenesis. We suggest that if the blockage of the ADRB receptors is maintained, the concentration of steroid hormones could decrease even more. Although not all rats in the EV group plus propranolol ovulated, there was a decrease in testosterone concentration in all animals treated with the ADRB receptor antagonist, which suggests variability in animals. It has been suggested that in prepubertal animals, the regulation of enzymes that participate in progesterone, testosterone and oestradiol synthesis does not occur in parallel. This suggests that the mechanisms of regulating the synthesis of each hormone are not regulated by the same signals and that the changes in the steroid hormone levels are not explained by the changes in gonadotropin secretion [54].

According to Fernandois et al., [23] there exists a correlation between reproductive aging and PCOS; both processes are accompanied by increased intraovarian sympathetic tone. In their study, it was proposed that after 2 months of blocking the ADRB, there was a reactivation of follicular development, an improved ovary cycling activity, an increased ovulation rate and a decrease in the number of cystic structures. Luna et al., [22] proposed that PCOS could be induced by ADRB activation in rats and could be prevented by simultaneous administration of an agonist and an antagonist of ADRB. In the present study, a single propranolol injection into the ovarian 


\section{Tyrosine hydroxylase}
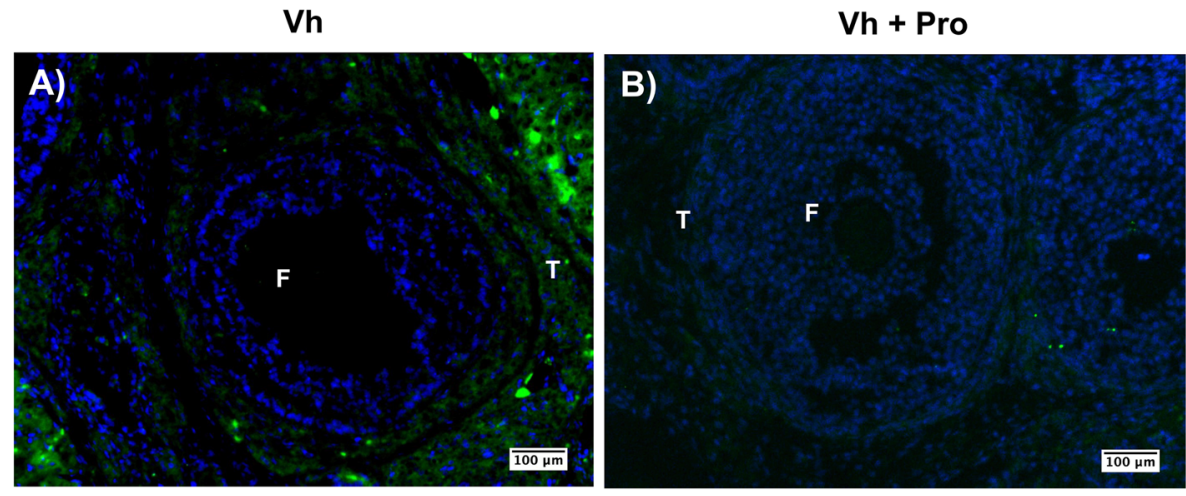

EV

EV + Pro
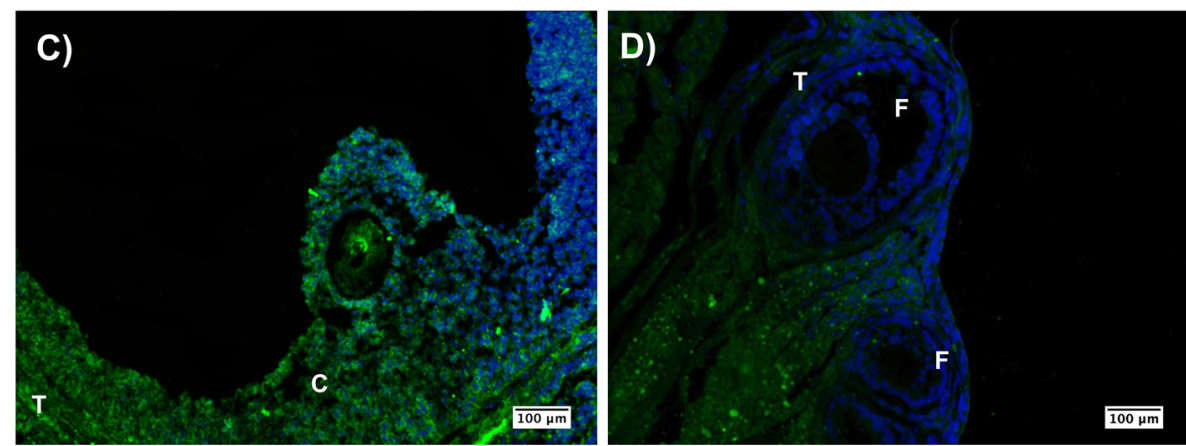

Negative control
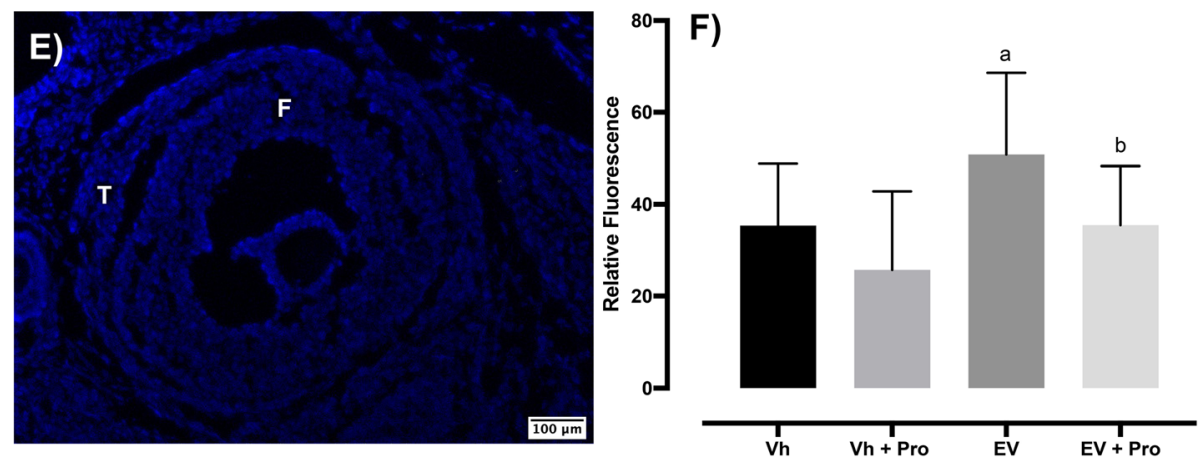

Fig. 3 Distribution of TH in ovaries of Vh (a) or EV-treated rats (c) and before the bilateral injection of propranolol (Pro) (b, d) into the ovarian bursas. e Negative control where the primary antibody was substituted with PBS. The ovarian sections were stained with anti-TH antibody (green color), and nuclear staining was performed with DAPI (blue color). TH is observed throughout the ovary, including the F: follicle and T: Theca cell. Bar $100 \mu \mathrm{m}$. $\mathbf{f}$ ImageJ analysis of TH relative fluorescence means \pm SE ( $n=3$ animals per group with 10 pseudo-replicas per animal), ${ }^{a} p<0.05 \mathrm{vS}$ Vh group; ${ }^{b} p<0.05$ vs. EV group (one-way analysis of variance, followed by Tukey)

bursas of EV-rats showed ovarian morphology with follicular development and the presence of $\mathrm{CL}$, indicating that the animals ovulated. However, this treatment was not able to reestablish ovarian functions in all animals. Espinoza et al. [37] showed that chronic administration of guanethidine (a drug that destroys noradrenergic fibers), prior to the induction of PCOS with EV, prevents the blockage of ovulation and hyperandrogenism. However, animals that have already developed PCOS are not able to reduce testosterone levels; despite pharmacological denervation, neural signals arrive in the ovaries via the SON.

It is possible that when ADRB are blocked, NE acts on $\alpha$-adrenoreceptors, maintaining high testosterone levels, despite treatment with propranolol. Manni et al., [38] showed that the expression of ADRA1 was higher in the ovaries of rats with PCOS. Although the effect of the ADRA activation on ovarian steroidogenesis in PCOS rats has not been studied, it has been shown that in cultured granulosa cells obtained from 


\section{Dopamine $\beta$-hydroxylase}
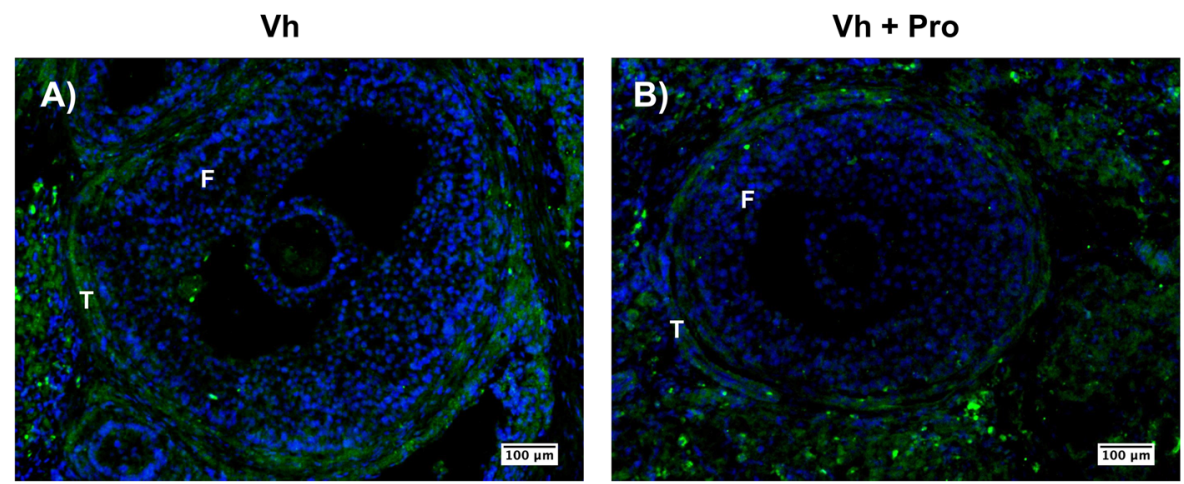

EV
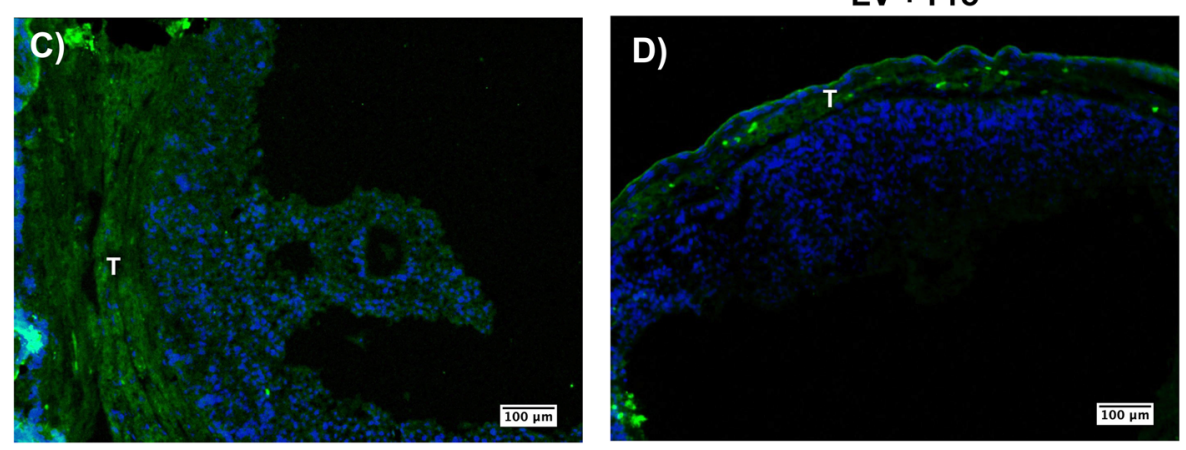

Negative control
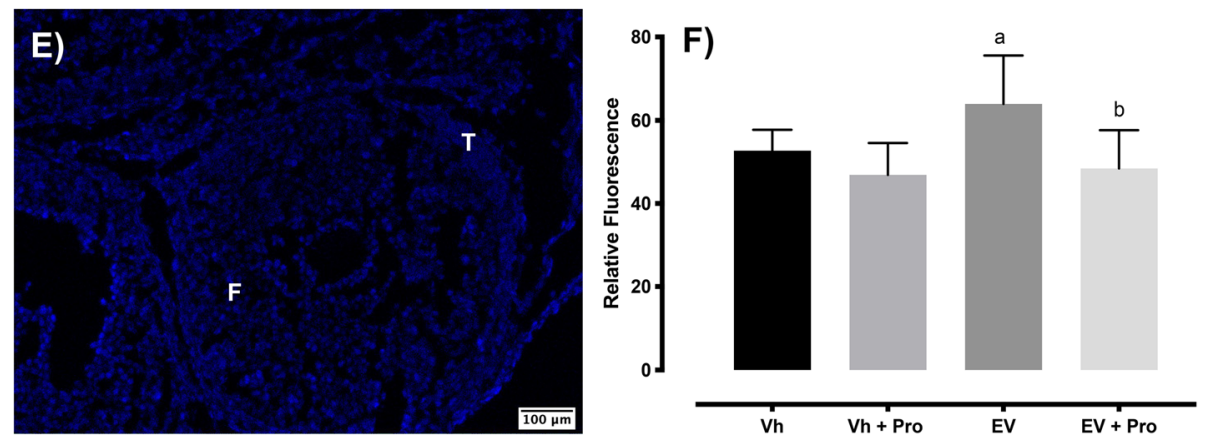

Fig. 4 Distribution of DBH in ovaries of Vh (a) or EV-treated rats (c) and before the bilateral injection with propranolol (Pro) (b-d) into the ovarian bursas. The ovarian sections were stained with anti-DBH antibody (green color), and nuclear staining was performed with DAPI (blue color). e Negative control where the primary antibody was substituted with PBS. DBH is observed throughout the ovary, including the F: follicle, T: theca cell. Bar $100 \mu \mathrm{m}$. f ImageJ analysis of DBH relative fluorescence means \pm SE ( $n=3$ animals per group with 10 pseudo-replicas per animal), ${ }^{a} p<0.05$ vs Vh group; ${ }^{b} p<0.05$ EV group (one-way analysis of variance, followed by Tukey)

adult rats, phenylephrine (an ADRA1A agonist) stimulates the secretion of progesterone [11], which is a precursor of testosterone.

According to Morales-Ledesma et al. [36] the NE release in EV-treated rats increased from the sympathetic fibers to ovaries. This change is associated with higher TH activity $[8,32,35]$. In the present study, we show that $\mathrm{TH}$ and $\mathrm{DBH}$ immunoreactivity is present in the theca-interstitial cells of EV-treated rats, and this activity is likely associated with the synthesis and secretion of testosterone. To our knowledge, this study is the first to show that a single propranolol injection into the ovarian bursas in EV-treated rats decreases TH immunoreactivity. These observations suggest that the functional activity of ovarian sympathetic tone is diminished by blocking ADRB. Likewise, DBH immunoreactivity is decreased in EV-treated rats. This finding suggests that the increase in $\mathrm{TH}$ activity produces a downregulation of DBH immunoreactivity in the ovaries as a way of producing negative feedback of NE synthesis. 


\section{Conclusions}

The results suggest that acute ovarian blocking of ADRB in animals with EV-induced PCOS improves the ovulation rate, decreases the testosterone levels and promotes follicular development by decreasing the hyperactivity of the ovarian noradrenergic system.

\section{Abbreviations}

ADR: Adrenoreceptors; ADRA: a-adrenoreceptor; ADRB: $\beta$-adrenoreceptor; $\mathrm{CL}$ : Corpora lutea; DBH: Dopamine $\beta$-hydroxylase; EV: Oestradiol valerate; FSH: Follicle stimulating hormone; LH: Luteinizing hormone; NE: Norepinephrine; NGF: Nerve growth factor; PBS: Phosphate buffer solution; PCOS: Polycystic ovarian syndrome; SON: Superior ovarian nerve; $\mathrm{TH}$ : Tyrosine hydroxylase; Vh: Vehicle; VN: Vagus nerve

\section{Acknowledgements}

We want to thank the "Programa de Becas Posdoctorales, UNAM" for their support in the realization of this study. We also thank the Biologist Roberto Chavira for participating in performing the ELISA to measure the steroids hormones concentrations.

\section{Authors' contributions}

BV and LML planned and designed the experiments. BV, LYDG, GR and JAE performed experiments. BV, CM, RD and LML devised the study, analyzed the data and wrote the manuscript. All authors read and approved the final manuscript.

\section{Funding}

This study was supported by UNAM-DGAPA-PAPIIT program IN217016 and IN216519. The author Berenice Venegas-Meneses was supported by the postdoctoral fellowship program UNAM-DGAPA 2016-2017.

\section{Availability of data and materials}

The datasets generated during and/or analyzed during the current study are available from the corresponding author on reasonable request.

\section{Ethics approval}

The animals used in this study were carried out according to the Mexican Law of Animal Treatment and Protection Guidelines (NOM-062-ZOO-1999). The institutional committee of the Facultad de Estudios Superiores Zaragoza, UNAM approved the experimental protocols. Every effort was made to minimize the number of animals in each experimental group and ensure minimal discomfort and pain in them.

\section{Consent for publication}

Not applicable.

\section{Competing interests}

The authors declare that they have no competing interests.

\section{Author details}

${ }^{1}$ Biology of Reproduction Research Unit, Physiology of Reproduction Laboratory, Facultad de Estudios Superiores Zaragoza, UNAM, AP 9-020, CP, 15000 México, DF, Mexico. ${ }^{2}$ Área de Procesos Celulares Fundamentales, Facultad de Ciencias Biológicas, Benemérita Universidad Autónoma de Puebla, 72570 Puebla, CP, Mexico. ${ }^{3}$ Centro de Investigación en Fisicoquímica de Materiales, Instituto de Ciencias, Benemérita Universidad Autónoma de Puebla, Puebla, Mexico.

Received: 31 July 2019 Accepted: 4 November 2019

Published online: 19 November 2019

\section{References}

1. Dumesic DA, Oberfield SE, Stener-Victorin E, Marshall JC, Laven JS, Legro RS. Scientific Statement on the Diagnostic Criteria, Epidemiology, Pathophysiology, and Molecular Genetics of Polycystic Ovary Syndrome. Endocr Rev. 2015;36(5):487-525. https://doi.org/10.1210/er.2015-1018.

2. Lizneva D, Suturina L, Walker W, Brakta S, Gavrilova-Jordan L, Azziz R. Criteria, prevalence, and phenotypes of polycystic ovary syndrome. Fertil Steril. 2016;106(1):6-15. https://doi.org/10.1016/j.fertnstert.2016.05.003.
3. De Leo V, Musacchio MC, Cappelli V, Massaro MG, Morgante G, Petraglia F. Genetic, hormonal and metabolic aspects of PCOS: an update. Reprod Biol Endocrinol. 2016;14:38. https://doi.org/10.1186/s12958-016-0173-x.

4. Matalliotakis I, Kourtis A, Koukoura O, Panidis D. Polycystic ovary syndrome: etiology and pathogenesis. Arch Gynecol Obstet. 2006;274(4):187-97. https://doi.org/10.1007/s00404-006-0171-x.

5. Pasquali R, Stener-Victorin E, Yildiz BO, Duleba AJ, Hoeger K, Mason H, et al. PCOS Forum: Research in Polycystic Ovary Syndrome Today and Tomorrow. Clinical endocrinology. 2011;74(4):424-33. https://doi.org/10.1111/j.13652265.2010.03956.x

6. Heider U, Pedal I, Spanel-Borowski K. Increase in nerve fibers and loss of mast cells in polycystic and postmenopausal ovaries. Fertil Steril. 2001;75(6):1141-7.

7. Dissen GA, Lara HE, Leyton V, Paredes A, Hill DF, Costa ME, et al. Intraovarian excess of nerve growth factor increases androgen secretion and disrupts estrous cyclicity in the rat. Endocrinology. 2000;141(3):1073-82. https://doi org/10.1210/endo.141.3.7396

8. Lara HE, Ferruz JL, Luza S, Bustamante DA, Borges Y, Ojeda SR. Activation of ovarian sympathetic nerves in polycystic ovary syndrome. Endocrinology. 1993;133(6):2690-5. https://doi.org/10.1210/endo.133.6.7902268.

9. Aguado LI, Ojeda SR. Prepubertal rat ovary: hormonal modulation of betaadrenergic receptors and of progesterone response to adrenergic stimulation. Biology of Reproduction. 1986;34(1):45-50. https://doi.org/10. 1095/biolreprod34.1.45.

10. Hernandez ER, Jimenez JL, Payne DW, Adashi EY. Adrenergic regulation of ovarian androgen biosynthesis is mediated via beta 2-adrenergic thecainterstitial cell recognition sites. Endocrinology. 1988;122(4):1592-602. https://doi.org/10.1210/endo-122-4-1592.

11. Wasilewska-Dziubinska E, Borowiec M, Chmielowska M, Wolinska-Witort E, Baranowska B. Alfa 1 adrenergic potentiation of progesterone accumulation stimulated by vasoactive intestinal peptide (VIP) and pituitary adenylate cyclase-activating polypeptide (PACAP) in cultured rat granulosa cells. Neuro Endocrinol Lett. 2002;23(2):141-8.

12. Mayerhofer A, Dissen GA, Costa ME, Ojeda SR. A role for neurotransmitters in early follicular development: induction of functional follicle-stimulating hormone receptors in newly formed follicles of the rat ovary. Endocrinology. 1997;138(8):3320-9. https://doi.org/10.1210/endo.138.8.5335.

13. Lara HE, McDonald JK, Ahmed CE, Ojeda SR. Guanethidine-mediated destruction of ovarian sympathetic nerves disrupts ovarian development and function in rats. Endocrinology. 1990;127(5):2199-209. https://doi.org/ 10.1210/endo-127-5-2199.

14. Burden HW. The adrenergic innervation of mammalian ovaries. In: BenJonathan N, Bahr JM, Weiner Rl, editors. Catecholamines as hormone regulators. New York: Raven Press; 1985;261-278.

15. Dorfman M, Arancibia S, Fiedler JL, Lara HE. Chronic Intermittent Cold Stress Activates Ovarian Sympathetic Nerves and Modifies Ovarian Follicular Development in the Rat. Biol Reprod. 2003;68(6):2038-43. https://doi.org/10. 1095/biolreprod.102.008318.

16. Morales-Ledesma L, Trujillo A, Apolonio J. In the pubertal rat, the regulation of ovarian function involves the synergic participation of the sensory and sympathetic innervations that arrive at the gonad. Reprod Biol Endocrinol. 2015:13:61. https://doi.org/10.1186/s12958-015-0062-8.

17. Chavez-Genaro R, Lombide P, Dominguez R, Rosas P, Vazquez-Cuevas F. Sympathetic pharmacological denervation in ageing rats: effects on ovulatory response and follicular population. Reprod Fertil Dev. 2007;19(8):954-60.

18. Goldman JM, Parrish MB, Cooper RL, McElroy WK. Blockade of ovulation in the rat by systemic and ovarian intrabursal administration of the fungicide sodium dimethyldithiocarbamate. Reprod Toxicol. 1997;11(2-3):185-90. https://doi.org/10.1016/s0890-6238(97)00005-1.

19. Itoh MT, Ishizuka B. a1-Adrenergic receptor in rat ovary: Presence and localization. Mol Cell Endocrinol. 2005;240(1-2):58-63. https://doi.org/10. 1016/j.mce.2005.05.012.

20. Laszlovsky I, Erdö SL. Characterization of $\beta$-adrenergic receptors in rat ovary. Eur J Pharmacol. 1983;96(1):101-4. https://doi.org/10.1016/00142999(83)90534-4.

21. Jordan AW. Changes in Ovarian $\beta$-Adrenergic Receptors During the Estrous Cycle of the Rat. Biol Reprod. 1981;24(2):245-8. https://doi.org/10.1095/ biolreprod24.2.245.

22. Luna SL, Neuman S, Aguilera J, Brown DI, Lara HE. In vivo beta-adrenergic blockade by propranolol prevents isoproterenol-induced polycystic ovary in adult rats. Horm Metab Res. 2012:44(9):676-81. https://doi.org/10.1055/s0031-1301304. 
23. Fernandois $D$, Lara $H E$, Paredes $A H$. Blocking of beta-adrenergic receptors during the subfertile period inhibits spontaneous ovarian cyst formation in rats. Horm Metab Res. 2012;44(9):682-7. https://doi.org/10.1055/s-0032-1304607.

24. Dominguez R, Gaitan CM, Mendez SA, Ulloa-Aquirre A. Effects of catecholaminergic blockade by haloperidol or propranolol at different stages of the oestrous cycle on ovulation and gonadotrophin levels in the rat. J Endocrinol. 1987;113(1):37-44. https://doi.org/10.1677/joe.0.1130037.

25. Maliqueo M, Benrick A, Stener-Victorin E. Rodent models of polycystic ovary syndrome: phenotypic presentation, pathophysiology, and the effects of different interventions. Semin Reprod Med. 2014;32(3):183-93. https://doi. org/10.1055/s-0034-1371090.

26. Peecher DL, Binder AK, Gabriel KI. Rodent models of mental illness in PCOS: The potential role of HPA dysregulation and lessons for behavioral researchers. Biol Reprod. 2018;100:590-600. https://doi.org/10.1093/biolre/ioy233.

27. Azziz R. Animal models for PCOS - not the real thing. Nature Reviews Endocrinology. 2017;13:-382. https://doi.org/10.1038/nrendo.2017.57.

28. Shaaban Z, Jafarzadeh Shirazi MR, Nooranizadeh MH, Tamadon A, Rahmanifar F, Ahmadloo S, et al. Decreased Expression of ArgininePhenylalanine-Amide-Related Peptide-3 Gene in Dorsomedial Hypothalamic Nucleus of Constant Light Exposure Model of Polycystic Ovarian Syndrome. Int J Fertil Steril. 2018;12(1):43-50. https://doi.org/10.22074/ijfs.2018.5206.

29. Shi D, Vine DF. Animal models of polycystic ovary syndrome: a focused review of rodent models in relationship to clinical phenotypes and cardiometabolic risk. Fertil Steril. 2012;98(1):185-93. https://doi.org/10.1016/j. fertnstert.2012.04.006.

30. Brawer JR, Munoz M, Farookhi R. Development of the polycystic ovarian condition (PCO) in the estradiol valerate-treated rat. Biol Reprod. 1986;35(3): 647-55.

31. Sotomayor-Zarate R, Dorfman M, Paredes A, Lara HE. Neonatal exposure to estradiol valerate programs ovarian sympathetic innervation and follicular development in the adult rat. Biol Reprod. 2008;78(4):673-80. https://doi. org/10.1095/biolreprod.107.063974.

32. Barria A, Leyton V, Ojeda SR, Lara HE. Ovarian steroidal response to gonadotropins and beta-adrenergic stimulation is enhanced in polycystic ovary syndrome: role of sympathetic innervation. Endocrinology. 1993; 133(6):2696-703. https://doi.org/10.1210/endo.133.6.8243293.

33. Stener-Victorin E, Lundeberg T, Waldenstrom U, Manni L, Aloe L, Gunnarsson S, et al. Effects of electro-acupuncture on nerve growth factor and ovarian morphology in rats with experimentally induced polycystic ovaries. Biol Reprod. 2000;63(5):1497-503.

34. Rosa ESA, Guimaraes MA, Padmanabhan V, Lara HE. Prepubertal administration of estradiol valerate disrupts cyclicity and leads to cystic ovarian morphology during adult life in the rat: role of sympathetic innervation. Endocrinology. 2003;144(10):4289-97. https://doi.org/10. 1210/en.2003-0146

35. Manni L, Holmäng A, Lundeberg T, Aloe L, Stener-Victorin E. Ovarian expression of alpha (1)- and beta (2)-adrenoceptors and p75 neurotrophin receptors in rats with steroid-induced polycystic ovaries. Autonomic Neuroscience. 2005;118(1-2): 79-87. https://doi.org/10.1016/.autneu.2005.01.004.

36. Morales-Ledesma L, Linares R, Rosas G, Moran C, Chavira R, Cardenas M, et al. Unilateral sectioning of the superior ovarian nerve of rats with polycystic ovarian syndrome restores ovulation in the innervated ovary. Reprod Biol Endocrinol. 2010;8:99. https://doi.org/10.1186/1477-7827-8-99.

37. Espinoza JA, Alvarado W, Venegas B, Dominguez R, Morales-Ledesma L. Pharmacological sympathetic denervation prevents the development of polycystic ovarian syndrome in rats injected with estradiol valerate. Reprod Biol Endocrinol. 2018;16(1):86. https://doi.org/10.1186/s12958-018-0400-8.

38. Manni L, Lundeberg T, Holmang A, Aloe L, Stener-Victorin E. Effect of electro-acupuncture on ovarian expression of alpha (1)- and beta (2)adrenoceptors, and p75 neurotrophin receptors in rats with steroid-induced polycystic ovaries. Reprod Biol Endocrinol. 2005;3:21. https://doi.org/10.1186/ 1477-7827-3-21.

39. Manni L, Cajander S, Lundeberg T, Naylor AS, Aloe L, Holmang A, et al. Effect of exercise on ovarian morphology and expression of nerve growth factor and alpha(1)- and beta(2)-adrenergic receptors in rats with steroidinduced polycystic ovaries. J Neuroendocrinol. 2005;17(12):846-58. https:// doi.org/10.1111/j.1365-2826.2005.01378.x.

40. Venegas-Meneses B, Padilla JF, Juarez CE, Moran JL, Moran C, Rosas-Murrieta $\mathrm{NH}$, et al. Effects of ovarian dopaminergic receptors on ovulation. Endocrine. 2015;50(3):783-96. https://doi.org/10.1007/s12020-015-0636-4.
41. Bagavandoss P, Grimshaw S. Distribution of adenylyl cyclases in the rat ovary by immunofluorescence microscopy. Anat Rec (Hoboken). 2012; 295(10):1717-26. https://doi.org/10.1002/ar.22550.

42. Bagavandoss $\mathrm{P}$, Grimshaw $\mathrm{S}$. Temporal and spatial distribution of the cannabinoid receptors (CB1, CB2) and fatty acid amide hydroxylase in the rat ovary. Anat Rec (Hoboken). 2010;293(8):1425-32. https://doi.org/10.1002/ar.21181.

43. Stener-Victorin E. Hypothetical physiological and molecular basis for the effect of acupuncture in the treatment of polycystic ovary syndrome. Mol Cell Endocrinol. 2013;373(1-2):83-90. https://doi.org/10.1016/.mce.2013.01.006.

44. Sverrisdottir YB, Mogren T, Kataoka J, Janson PO, Stener-Victorin E. Is polycystic ovary syndrome associated with high sympathetic nerve activity and size at birth? Am J Physiol Endocrinol Metab. 2008;294(3):E576-81. https://doi.org/10.1152/ajpendo.00725.2007.

45. Lara HE, Porcile A, Espinoza J, Romero C, Luza SM, Fuhrer J, et al. Release of norepinephrine from human ovary: coupling to steroidogenic response. Endocrine. 2001;15(2):187-92. https://doi.org/10.1385/endo:15:2:187.

46. Lara HE, Dissen GA, Leyton V, Paredes A, Fuenzalida H, Fiedler JL, et al. An increased intraovarian synthesis of nerve growth factor and its low affinity receptor is a principal component of steroid-induced polycystic ovary in the rat. Endocrinology. 2000;141(3):1059-72. https://doi.org/10.1210/endo.141.3.7395.

47. Linares R, Hernandez D, Moran C, Chavira R, Cardenas M, Dominguez R, et al. Unilateral or bilateral vagotomy induces ovulation in both ovaries of rats with polycystic ovarian syndrome. Reprod Biol Endocrinol. 2013;11:68. https://doi.org/10.1186/1477-7827-11-68.

48. Adashi EY, Hsueh AJ. Stimulation of beta 2-adrenergic responsiveness by follicle-stimulating hormone in rat granulosa cells in vitro and in vivo. Endocrinology. 1981;108(6):2170-8. https://doi.org/10.1210/endo-108-6-2170

49. Aguado LI, Petrovic SL, Ojeda SR. Ovarian beta-adrenergic receptors during the onset of puberty: characterization, distribution, and coupling to steroidogenic responses. Endocrinology. 1982;110(4):1124-32. https://doi. org/10.1210/endo-110-4-1124.

50. Fohr KJ, Mayerhofer A, Sterzik K, Rudolf M, Rosenbusch B, Gratzl M. Concerted action of human chorionic gonadotropin and norepinephrine on intracellular-free calcium in human granulosa-lutein cells: evidence for the presence of a functional alpha-adrenergic receptor. J Clin Endocrinol Metab. 1993;76(2):367-73. https://doi.org/10.1210/jcem.76.2.8381798.

51. Webley GE, Luck MR, Hearn JP. Stimulation of progesterone secretion by cultured human granulosa cells with melatonin and catecholamines. J Reprod Fertil. 1988;84(2):669-77.

52. Ojeda SR, Lara HE. Role of the Sympathetic Nervous System in the Regulation of Ovarian Function. In: Pirke KM, Wuttke W, Schweiger U, editors. The Menstrual Cycle and Its Disorders: Influences of Nutrition, Exercise and Neurotransmitters. Berlin: Springer Berlin Heidelberg; 1989. p. 26-32.

53. Parra C, Fiedler JL, Luna SL, Greiner M, Padmanabhan V, Lara HE. Participation of vasoactive intestinal polypeptide in ovarian steroids production during the rat estrous cycle and in the development of estradiol valerate-induced polycystic ovary. Reproduction. 2007;133(1):147-54. https:// doi.org/10.1530/rep.1.01214.

54. Morales-Ledesma L, Vieyra E, Ramirez DA, Trujillo A, Chavira R, Cardenas M, et al. Effects on steroid hormones secretion resulting from the acute stimulation of sectioning the superior ovarian nerve to pre-pubertal rats. Reprod Biol Endocrinol. 2012;10:88. https://doi.org/10.1186/1477-7827-10-88.

\section{Publisher's Note}

Springer Nature remains neutral with regard to jurisdictional claims in published maps and institutional affiliations.

\section{Ready to submit your research? Choose BMC and benefit from:}

- fast, convenient online submission

- thorough peer review by experienced researchers in your field

- rapid publication on acceptance

- support for research data, including large and complex data types

- gold Open Access which fosters wider collaboration and increased citations

- maximum visibility for your research: over $100 \mathrm{M}$ website views per year

At $\mathrm{BMC}$, research is always in progress. 